OPEN ACCESS

Edited by:

Geoff Anthony Lindsay,

University of Warwick,

United Kingdom

Reviewed by:

Gregor Ross Maxwell,

UiT the Arctic University of

Norway, Norway

Jean Ware

Bangor University, United Kingdom

Tom Bailey,

University of Warwick,

United Kingdom

*Correspondence:

Susana Castro-Kemp

susana.castro-kemp@

roehampton.ac.uk

Specialty section:

This article was submitted to Special Educational Needs,

a section of the journal

Frontiers in Education

Received: 06 February 2019

Accepted: 08 July 2019

Published: 23 July 2019

Citation:

Castro-Kemp S, Palikara O and

Grande C (2019) Status Quo and

Inequalities of the Statutory Provision

for Young Children in England, 40

Years on From Warnock.

Front. Educ. 4:76

doi: 10.3389/feduc.2019.00076

\section{Status Quo and Inequalities of the Statutory Provision for Young Children in England, 40 Years on From Warnock}

\author{
Susana Castro-Kemp ${ }^{1 *}$, Olympia Palikara ${ }^{1}$ and Catarina Grande ${ }^{2}$ \\ ${ }^{1}$ School of Education, Roehampton University, London, United Kingdom, ${ }^{2}$ Faculty of Psychology and Education Sciences, \\ Porto University, Porto, Portugal
}

In England, the Children and Families Act 2014 has been regarded as the most radical change in the Special Educational Needs and Disability provision for decades. Building on the recommendations of the Warnock report and subsequent 1981 Education Act, the 2014 Act introduced the Education Health and Care plans to replace the Statements of Special Educational Needs, with the view to promote holistic and participation-focused provision. This study aimed to examine and compare the quality of the Education Health and Care plans developed in some of the most deprived and some of the most affluent regions in England, with a particular focus on young children, given the well-documented instrumental role of early childhood intervention. The Education Health and Care plans of 71 children aged 4-8 years old were gathered and a systematic analysis of the needs and outcomes reported in those plans was conducted. Results show that the pattern of needs is similar across diagnostic categories, with the exception of mobility needs. However, more affluent local authorities provide more detailed descriptions of certain types of needs (related to mental functions and sensory functions) and higher quality outcomes. Special settings also present more detailed descriptions of some needs than mainstream settings, as well as higher quality outcomes. The higher the number of reported mental functions needs (related to emotional regulation), the higher the quality of the outcomes written for those children. However, the quality of the outcomes is markedly low across plans, local authorities and settings. These results show that the status quo of the Special Educational Needs and Disability policy and provision is still characterized by marked social inequality and specialized work-force disparities, 40 years on from the first Warnock report and the commitment to full inclusion.

Keywords: warnock, SEND, EHC, inequalities, children, early childhood intervention, ECI

\section{INTRODUCTION}

Inclusion, and in particular inclusive provision in early years, has been on the international education agenda for decades. The Warnock report (Department of Education and Science, 1978) was instrumental in establishing the direction of special educational needs provision toward full inclusion in mainstream settings. Additionally, it provided progressive insight and evidence-based arguments on the need to consider children under the age of five, with no minimum age limit, 
as part of the full inclusion initiative. These powerful statements were supported by contemporary studies of that time, highlighting early childhood as a critical period for change, due to the plasticity of development in this age range, alongside a fast pace of growth (e.g., Caldwell, 1970, 1974; Cave and Maddison, 1980). In a similarly progressive way, the Warnock report (Department of Education and Science, 1978) underlined the role of multi-professional assessment for a holistic and more efficient provision, especially in very young children who might not have started school or nursery yet, but who could still benefit from special education.

The Warnock report's recommendations were groundbreaking and they were followed by other international policies that have been long-standing pillars of special education provision worldwide: the Salamanca Statement and Framework for Action on Special Needs Education (Unesco, 1994), calling for all governments to ensure and prioritize the education of all children through inclusive schooling, and the United Nations Convention on the Rights of Persons with Disabilities (UN, 2006), which the United Kingdom ratified in 2009.

In England, the Warnock Report (Department of Education and Science, 1978) led to the publication of the Education Act 1981, which regulated that special provision should be implemented by Local Education Authorities for any children with special needs. However, a detailed Code of Practice with specific guidelines for Local Education Authorities was only issued following the 1993 Education Act, as a result of extensive consultation with education, health and social care services. Despite nearly three decades of a clear policy commitment toward full inclusion, in 2005 Baroness Warnock released a pamphlet questioning the way in which the inclusion agenda had been implemented, in many fronts. For instance, Warnock (2005) posited that the statementing procedure was not effective, with unclear criteria as to who and when should be in receipt of the statutory documents; additionally, she claimed that a small number of specialist schools was necessary, as the mainstream provision seemed to be unable to cope with the demands of full inclusion, with high numbers of children being supported by unqualified teaching assistants.

The publication of this pamphlet gave rise to an important debate about the course of inclusive provision in England, with many criticizing Warnock for providing a "new look" on special educational needs provision which was misinformed, dismissing 25 years of research in the area (Barton, 2005). This debate (which continues today and is also the focus of current research) started as early childhood intervention (ECI) was rising internationally as a field of research and practice on its own, conceived as familycentered (Bruder, 2000), with consideration for the family's own context and background (Shonkoff et al., 2000) and multidisciplinary in nature (King et al., 2009). Opposite to the study of early childhood development, ECI does not focus solely on developmental acquisitions and milestones for children, but on the goodness-of-fit between the developing child and her family and community contexts (Simeonsson et al., 1986; Dunst et al., 2014). Moreover, it is meant to support all children who are restricted in their development and participation, even if they do not have a diagnosable disability (Halpern, 2000).
The field of ECI has flourished in the twenty-first century, especially in Europe (Carpenter et al., 2009), and in the United States, where a variety of models were proposed (Dunst, 2000; Dunst and Trivette, 2009). Although England's policy for ECI has been largely influenced over the years by this international trend toward inclusion in early years (Parton, 2006; Carpenter and Campbell, 2008), a state-funded ECI system is still not part of the political agenda (Faulkner and Coates, 2013). It was the coalition Governments' plan to implement free nursery education and care available to all, especially to those from disadvantaged backgrounds (Faulkner and Coates, 2013), however this is still not in place today; even with the creation of the Early Intervention Foundation in 2013, a charity whose aim is to improve the lives of children and young people at risk of experiencing poor outcomes, fewer children with disabilities have been eligible for certain benefits such as council care, over the years, and many are off the radar (National Children's Bureau, 2017).

Currently, the policy for provision for children with special educational needs and disabilities in England is regulated by the Children and Families Act 2014 and the respective SEND Code of Practice, which apply from birth to 25 years of age, and therefore account for the provision of very young children (Legislation.gov.uk, 2014; Department for Education Department of Health, 2015). This new policy has been regarded as the most radical change of the last few decades of SEND provision (Norwich, 2014), probably since the first Warnock report. Under this new regulation, statements of special educational needs are now replaced with education health and care plans (EHC plans), which should be designed as holistic documents (involving education, health and social care provision), include the child's own needs and aspirations and those of her family, and specify outcomes that are workable and functional (the SEND Code of Practice suggests these should be SMART_specific, measurable, attainable, realistic, and time-framed) (Department for Education Department of Health, 2015). Reactions to this new policy have not been short of controversy. Claims that it lacked guidance on how to implement changes and that it was ignoring international models and standards for classifying disability, such as the International Classification of Functioning, Disability, and Health (Norwich, 2014; Castro and Palikara, 2016), were followed by specific evidence of the problems encountered when implementing the Education Health and Care planning process: a very large number of professionals seem to agree with the policy itself but appear frustrated with the ways in which it has been implemented, suggesting it's ineffective (Boesley and Crane, 2018; Palikara et al., 2018b); the analysis of the EHC plans shows that these are not being developed as the holistic documents they were conceived to be, but appear fragmented, of low quality and not recognizing the children's and families' own voices (Palikara et al., 2018a; Castro et al., 2019).

The overall purpose of this study was to add to the existing evidence on the EHC planning process for young children with SEND, in particular looking at inequalities at social and professional levels, by comparing some of the wealthiest and some of the most deprived areas of England (within Greater 
London), and different types of educational settings. Specifically, we examined the needs of children with SEND aged 4-8 as reported in their EHC plans, the quality of the outcomes written for these children, and the relationship between needs and outcomes, testing differences between geographical area and type of setting (mainstream or special setting). To this end, the following research questions were formulated: (a) How does the needs' pattern of young children in receipt of Education Health and Care plans in England differ by local authority, type of education setting and diagnosis? (b) How does the quality of the outcomes written for young children with Education Health and Care plans in England differ by local authority, type of educational setting and diagnosis? (c) How can the relationship between the needs pattern and outcomes written for children in the Education Health and Care plans be characterized?

\section{MATERIALS AND METHODS}

\section{Recruitment and Sample Characteristics}

The sample of this study $(N=71)$ was withdrawn from a larger sample of 265 EHC plans, gathered for the purpose of a larger research project looking at quality of EHC plans across age ranges, from early years to 25 years of age. To address the specific purpose of this study (examining the quality of plans developed for younger children, with a focus on those from deprived backgrounds, for the widely recognized importance of early intervention), a sub-sample was withdrawn from the original dataset, including only children up to 8 years of age. Recruitment was performed by sending letters to Greater London local authorities in close proximity to the area where the research team is based. Because the process of finalizing EHC plans between 2015 and 2018 was slower than initially predicted by the UK government, the sampling area has expanded reaching 7 local authorities in total. Once a meeting was agreed with the SEND representative for each local authority in order to obtain their support and agreement regarding participation in this research, meetings were arranged with individual schools. Those schools that have agreed to participate in the study, liaised with parents and guardians of children and young people with EHC plans by sending information sheets and consent forms about the research project. Opt-in consent forms were sent by the parents/guardians directly to either the research team or to the respective school, after which the EHC plan would be released in hard copy or digital copy, as per the family and school's preference. All digital copies were kept in password protected files and hard copies in locked filing cabinets, accessible by the core research team only. Ethical approval to undertake this study was obtained by the University of Roehampton's Ethics Committee of the hosting research institution. The research team followed the British Psychological Society Code of Human Research Ethics as well as the British Educational Research Association Ethical Guidelines for Educational Research. The children were aged between 4 and 8 years old and attended educational settings in 7 Greater London local authorities which were included in the study; for the purpose of examining differences between local authorities in the current study, and to ensure total anonymity, these were grouped into three clusters, according to the Income
Deprivation Affecting Children's Index (IDACI; Smith et al., 2015): the local authorities ranked within the top 25\% nationally, which are the most deprived in the country, the local authorities ranked within the bottom $25 \%$ local authorities nationally (which are some of the most affluent in the country) and two local authorities ranked within the two mid quartiles of the national IDACI distribution. In relation to the type of school setting that children attend, 57 children come from mainstream schools and 14 attend special schools; 16 are female and 55 are male. In terms of age distribution, the sample has one 4 year-old child, two 5 year-olds, twenty-two 6 year-olds, twenty-seven 7 year olds and nineteen 8 year-olds. All plans included diagnosis information within the health needs section: 34 children had a diagnosis of autism spectrum disorder (ASD), 8 children had a diagnosis of Speech Language and Communication difficulties (SLC) and 29 children had other diagnoses such as genetic syndromes, physical disabilities, multisensory impairments and hearing impairments and as described in their plans, within the health needs section.

\section{Instruments and Materials}

The content of the EHC plans was mapped to the International Classification of Functioning Disability and Health for children and youth (ICF-CY; World Health Organization, 2007), for the possibility that this system offers of coding disability-related content in a universal language that has been endorsed by the World Health Organization and widely used for research purposes in this area. This is an extensive classification system covering all areas of functioning, from Body functions, to Activities and Participation, influenced by a variety of Environmental Factors. Each aspect of functioning is classified with one alphanumeric code comprised by a letter to designate the component (whether it is a body function, a structure, an activity or form of participation or an environmental factor), followed by a numeric code to designate the specific function/domain-for example d130 refers to the chapter learning and applying knowledge (d1), and specifically to copying (30). Therefore, the system contemplates various levels of specification. In the current study, only the chapter level (1st level of specification) was considered. It was not the purpose of this study to detail the needs of the children using the ICF$\mathrm{CY}$ language, but rather to condense the content of the needs' sections of the EHC plans into broad categories, for the purpose of examining differences between contexts. This is an innovative aspect of the methodology adopted in the study, as to date there have been only one study using the ICF system to support the analysis of EHC plans, and that was focused solely on section of the plans (Palikara et al., 2018a).

The Goal Functionality Scale II (McWilliam, 2005) was used to rate the quality of the outcomes included in the EHC plans. This scale was designed with the specific objective of rating the extent to which outcomes designed for provision for young children are functional. The scale is comprised of 7 items: (a) indication of the routine in which the child will participate [criterion 1], (b) specification of the desired behavior [criterion 2], (c) relevance of the specified behavior for the child's overall participation [criterion 3], (d) quantification of the acquisition criterion [criterion 4], (e) relevance of the acquisition 
criterion (included in a daily routine) [criterion 5], (f) presence of a generalization criterion [criterion 6], and (g) presence of a timeframe criterion [criterion 7]. Each outcome is rated independently on a scale of 1-4: not at all, somewhat, much, or very much. The match between these items and the SMART criteria proposed by the SEND Code of Practice for developing outcomes in the EHC plans is clear and has been extensively discussed elsewhere (Castro et al., 2019). The scale has also been used in similar studies with very high levels of interrater agreement (93\% and above) (e.g., Boavida et al., 2010; Rakap, 2015).

\section{Data Analysis}

In order to address the first research question (How does the needs' pattern of young children in receipt of Education Health and Care plans in England differ by local authority, type of education setting and diagnosis?), we focused our analyses on sections B (education needs), C (health needs), $\mathrm{D}$ (social care needs), and E (outcomes) of the EHC plans. Here, individual statements expressing needs of the children were extracted and mapped on to the ICF-CY classification system, following a procedure of deductive content analysis adopted previously in similar studies (Castro et al., 2014; Palikara et al., 2018a); however, only the chapter level was considered in this analysis, as the purpose was to obtain broad categories of need, to support the examination of differences between contexts. A statement was considered relevant when it expressed one need of the child; each need was coded individually. In order to enhance the trustworthiness of the coding, 20\% of the outcomes analyzed were independently coded by a second researcher and final agreement obtained in those cases where coding differed. This proportion of outcomes was sufficient for obtaining high levels of agreement (90\%). Statistical analyses were conducted with series of Poisson regression and negative binomial regression tests for examining differences in the likelihood of frequency of needs between local authorities, types of school (mainstream and special settings) and the type of diagnosis (ASD, SLC, and other). Poisson regression analysis was performed for those dependent variables in which all assumptions for running this test were met: mental functions needs [ratio mean/variance $=0.99$ ], communication needs [ratio mean/variance $=0.91$ ], interpersonal interaction needs [ratio mean/variance $=1.06]$, general tasks and demands needs [ratio mean/variance $=0.95$ ], and neuromusculoskeletal needs [ratio mean/variance $=1.1]$. Overdispersion was found for play and school participation needs [ratio mean $/$ variance $=1.3$ ], self-care $[$ ratio mean/variance $=1.2$ ], mobility [ratio mean/variance $=1.8$ ], sensory functions [ratio mean/variance $=1.3$ ] and learning and applying knowledge needs [ratio mean/variance $=1.3$ ]; in these cases, negative binomial regression was used, as recommended by Cameron and Trivedi (1990) and Green (2003). Wald Chi-square statistics was chosen over likelihood ratio given the relatively small sample size.

In order to address the second research question (How does the quality of the outcomes written for young children with Education Health and Care plans in England differ by local authority, type of educational setting and diagnosis?), we focused on the analysis of section E (the outcomes) in the EHC plans, and the GFS II (McWilliam, 2005) was used to rate each one of the outcomes on a scale from 1 to 4: not at all, somewhat, much, or very much. $10 \%$ of the outcomes were randomly selected using an automatic number generator and cross-checked by two coders; where agreement was not reached, a third judge with similar expertise was called to support decision-making regarding the final coding, in order to increase trustworthiness, as performed in other similar studies (Castro et al., 2013, 2019). In order to test the likelihood of frequency of high quality ratings per local authority, type of school and type of need, assumptions for running ordinal logistic regression were tested; Because the assumption of proportional odds required to perform ordinal logistic regression was not met, the outcome variables (quality criteria) were converted into dichotomous variables where low quality includes not at all and somewhat and high quality includes much and very much ratings. Binomial Logistic Regression was run to test the likelihood of having high quality ratings across the GFS-II criteria per local authority, type of settings and type of need.

In order to address the third research question (How can the relationship between the needs pattern and outcomes written for children in the Education Health and Care plans be characterized?), Pearson correlation analysis was run between these variables.

Statistical analyses were conducted using the Statistical Package for Social Sciences Software, version 24.

\section{RESULTS}

The overall purpose of this study was to examine potential inequalities in the current EHC planning process for children with SEND in the wealthiest and the most deprived areas of England (which are in Greater London). Specifically, we examined the needs of children with SEND aged 4-8 as reported in their EHC plans, the quality of the outcomes written for these children, and the relationship between needs and outcomes, testing differences between geographical area and type of setting. These results are presented in more detail in the following sections, which cover the pattern of needs identified in the EHC plans analyzed, the quality of the outcomes included in those plans and the relationship between needs and outcomes.

\section{The Pattern of Needs of Young Children With EHC Plans}

The summary of specific needs observed and reported in the EHC plans is illustrated in Figure 1: 1,473 statements were identified as reporting specific needs of the children within sections $B$ (education needs), C (health needs), and D (social care needs) of the EHC plans analyzed. Most needs reported are related to learning and applying knowledge (241 out of 1,473 statements); these include statements on learning to read, learning to write and early numeracy skills, but also learning basic and complex concepts [e.g., "She needs particular support to perceive, copy and manage visual-spatial information in her environment, as well as 


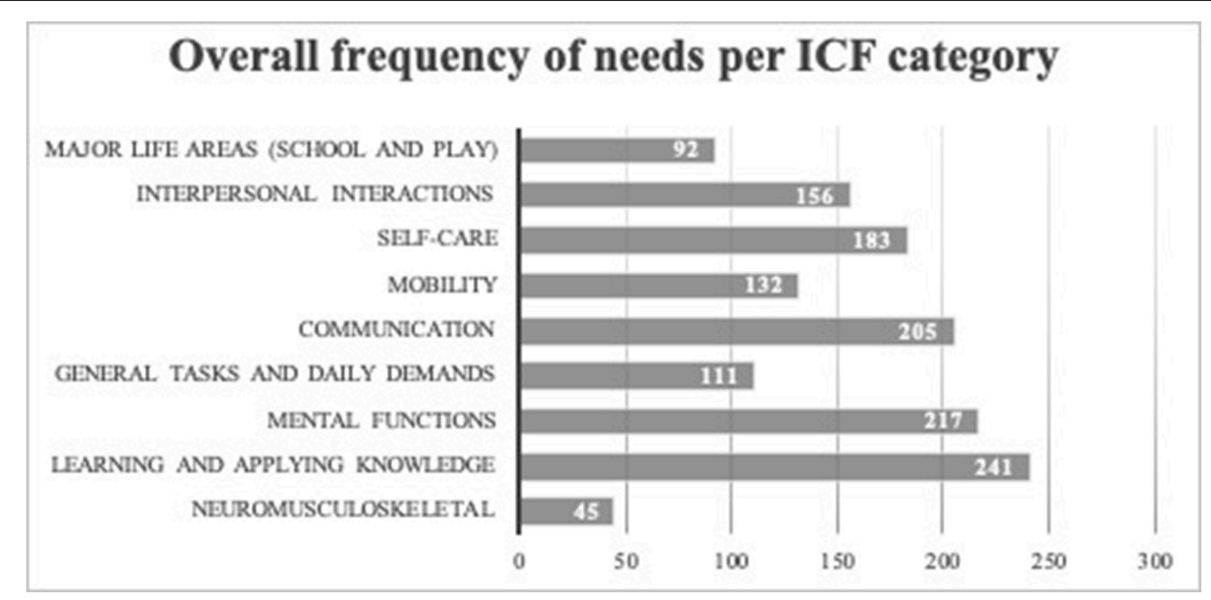

FIGURE 1 | Frequency of needs reported in the EHC plans per category of need.

to develop her skills in thinking and reasoning, with non-verbal information and to develop her skills in matching, sorting and categorizing" (EHC plan number 36 ); and " $D$. is at a pre-reading and literacy level and he is not yet counting with understanding" (EHC plan number 186)]. The following most frequent type of need reported were mental functions $(n=217)$, in particular functions related to emotional regulation and self-control issues [e.g., " $H$. can protest by lying on the floor as a way of opting out of activities" (EHC plan number 182)]; the following most frequent type of need were communication issues $(n=205)$, relating to understanding and expressing language in a variety of formats [e.g., "She follows general classroom instructions, when the instruction is supported by adults using signs for transition and natural gesture" (EHC plan number 87]. Other frequent needs reported were self-care needs $(n=183)$ relating to toileting, washing oneself or eating [e.g., "He is not yet able to put his shoes, AFOs and socks back on himself and struggles to manage his smock if it is taken off him. He cannot dress or undress himself without assistance." (EHC plan number 60)], interpersonal interactions ( $n=156)$ which refer to the ability to maintain, initiate and regulate relationships with peers and adults [e.g., "She can sometimes hit others for getting too close to her when she does not want it" (EHC plan number 102)], mobility $(n=132)$, relating to fine motor skills and gross motor skills [e.g., "There are concerns around N.'s gross motor movements and spatial awareness" (EHC plan number 105)], general tasks and demands $(n=111)$, relating to the ability to complete required tasks in groups or independently [e.g., " $B$. has difficulties sustaining his attention in whole class activities and shifting his attention between tasks. He is not yet able to attend to an adult-led task for more than a few minutes" (EHC plan number 91)], sensory functions $(n=91)$, often referring to sensory overload by the children, or sensory seeking behaviors [e.g., "A. has some sensory processing needs, particularly in relation to noise and touch. He can experience sensory overload, particularly in unpredictable, noisy environments" (EHC plan number 200)], major life areas such as the ability to play on his/her own and with peers $(n=92)$ [e.g., "F. chooses to play his own self-directed play" (EHC plan number

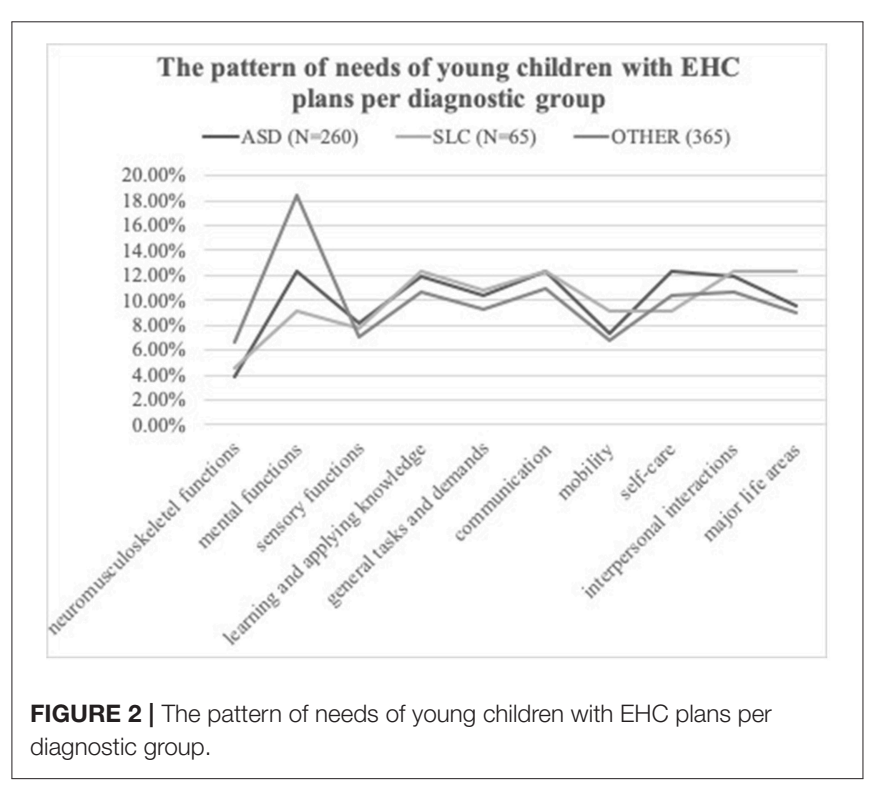

231)]; and neuromusculoskeletal functions $(n=45)$, referring to the ability to walk appropriately and perform other essential movements [e.g., "H. Has some postural weakness and can be clumsy" (EHC plan number 187)].

Figure 2 shows the profile of needs of the sample of children whose plans were included in this study across the main three types of diagnoses-ASD, SLC, and others.

As a result of the Poisson regression analysis conducted, it was observed that there are no statistically significant differences between types of diagnosis in relation to the frequency of reported mental functions as needs (Wald $\chi^{2}(2)=0.63$, $p=0.731)$ communication needs (Wald $\chi^{2}(2)=1.29, p=0.52$ ), interpersonal interaction needs (Wald $\chi^{2}(2)=1.73, p=0.42$ ), general tasks and demands (Wald $\left.\chi^{2}(2)=0.04, p=0.98\right)$, and neuromusculoskeletal needs (Wald $\chi^{2}(2)=3.77, p=0.15$ ). Results from the negative binomial regression conducted show 
that there are no significant statistical differences between diagnoses in the reported frequencies of play and participation in school needs (Wald $\chi^{2}(2)=0.33, p=0.85$ ), self-care needs (Wald $\chi^{2}(2)=0.84, p=0.66$ ), sensory functions (Wald $\chi^{2}$ $(2)=3.75, p=0.15$ ) and learning and applying knowledge (Wald $\left.\chi^{2}(2)=0.030, p=0.985\right)$; a statistical significant difference was observed in relation to mobility needs, where children classified as having "other" diagnoses had a higher reported frequency of need $(M=2.62, S D=2.26)$ when compared to children with A child included in the group of OTHER diagnoses is 2.57 times in the ASD group (95\% CI $[1.32,5.03])$.

Looking at the number of sections completed in the EHC plans analyzed (see Table 1) that refer to the children's needs, we have observed that in the majority of the plans $(n=37)$, both the Education (section B) and health needs (Section C) sections were completed; however, it is important to note that in 24 of these plans, the Health section merely described the diagnosis of the child (ASD, SLC, or other); the remaining EHC plans described other specific health needs such as asthma, eczema, or seizures, for example.

We examined whether the frequency of needs reported in the young children's EHC plans differed between local authorities. Results from Poisson regression and negative binomial regression show statistically significant differences between local authorities $\chi^{2}(2)=13.61, p=0.001$ ) needs and sensory needs (Wald $\left.\chi^{2}(2)=9.31, p=0.010\right)$, respectively. A child included in the top 25\% IDACI local authorities, and therefore within the most deprived regions, has 2.69 times fewer reported mental function needs than a child included in any of the other two local authority groups (95\% CI $[1.87,3.58])$; similarly, a child included in the most deprived group has 2.55 times fewer reported sensory needs than a child included in the most affluent group (95\% CI $[1.27,5.11])$. There are no statistically significant differences between local authorities in relation to other types of need: communication (Wald $\chi^{2}(2)=2.46, p=0.29$ ), interpersonal interactions (Wald $\chi^{2}(2)=0.341, p=0.84$ ), general tasks and demands (Wald $\chi^{2}(2)=4.84, p=0.089$ ), neuromusculoskeletal (Wald $\chi^{2}(2)=2.37, p=0.30$ ), play and participation in school life (Wald $\chi^{2}(2)=3.79, p=0.284$ ), self-care (Wald $\chi^{2}$ $(2)=0.433, p=0.805)$, mobility (Wald $\left.\chi^{2}(2)=1.49, p=0.485\right)$ and learning and applying knowledge (Wald $\chi^{2}(2)=0.53$, $p=0.77)$.

There are no differences between local authorities in relation to the sections of the EHC plans that have been completed $\left(\chi^{2}(6)=7.48, p=0.28\right)$.

Poisson regression analysis revealed statistically significant differences between the distributions of the types of school placement (mainstream or special settings) in relation to the frequency of reported communication needs $\left(\chi^{2}(1)=14.99\right.$, $p<0.001)$ and general tasks and demands $\left(\chi^{2}(6)=3.21\right.$, $p=0.073)$. Children included in special settings have 4.4 times more frequently reported communication needs (95\% CI $[3.45,5.68])$ and 2 times more frequently reported needs related to general tasks and demands (95\% CI $[1.38,2.89])$ Autism $(M=1.03, S D=1.22)\left(\right.$ Wald $\left.\chi^{2}(2)=8.02, p=0.02\right)$; more likely to have reported mobility needs than a child included regarding the frequency of reported mental functions (Wald

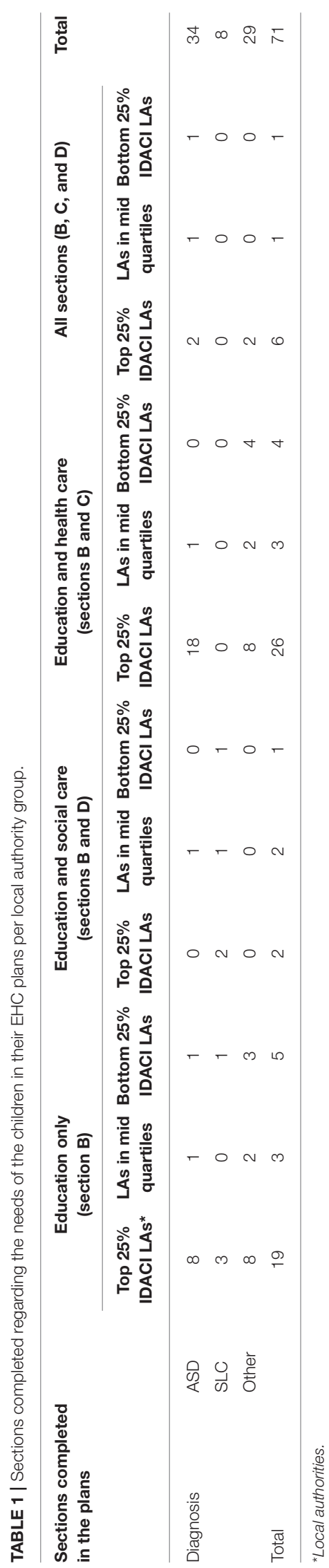

Frontiers in Education | www.frontiersin.org 
than children included in mainstream settings. Negative binomial logistic regression shows no statistically significant differences between types of school for the remaining needs: play and school participation $\left(\chi^{2}(1)=0.12, p=0.73\right)$, self-care $\left(\chi^{2}(1)=1.30, p=0.24\right)$, mobility $\left(\chi^{2}(1)=0.56\right.$, $p=0.45)$, sensory functions $\left(\chi^{2}(1)=0.016, p=0.90\right)$ and learning and applying knowledge $\left(\chi^{2}(1)=0.75\right.$, $p=0.38)$.

In sum, most needs are reported with similar frequency across diagnostic groups in the EHC plans, apart from mobility needs, which are more frequent in children in the category "other" diagnoses. Local authorities differ in the reporting of mental functions needs and sensory needs, with the most deprived areas reporting fewer needs. Schools differ in the reporting of communication needs and those related to general tasks and demands, with special settings reporting these needs more frequently than mainstream settings.

\section{The Outcomes Sought for Young Children With EHC Plans}

The 71 EHC plans gathered included a total of 878 outcomes, 654 of which were included in 51 EHC plans from the top 25\% IDACI areas (most deprived), 153 (11 EHC plans) from the bottom $25 \%$ IDACI areas (wealthiest) and 71 from the mid quarters of the IDACI distribution ( 9 plans). Mainstream school based EHC plans included more outcomes $(n=722)$, than special school based EHC plans $(n=156)$. Regarding the type of disability, 433 outcomes refer to children with ASD, 376 refer to children with other types of disability and 69 outcomes refer to children with SLC.

Tables 2, 4, 5 illustrate the overall quality of the outcomes designed for these children, based on the percentage of high and low quality ratings made with the GFS II, per local authority and type of school, respectively. The overall quality is markedly low. Table 3 shows parameter estimates resulting from the

TABLE 2 | Percentage of high quality outcome ratings per local authority across GFS I| criteria.

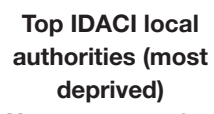

$N$ outcomes $=654$

\section{Middle range IDACI local authorities \\ $N$ outcomes $=71$}

\author{
Bottom IDACI local authorities \\ (wealthiest)
}

$N$ outcomes $=153$
Focuses on participation in daily routine

Specifies the behavior the child should perform

Highlights a skills useful for participation

Mentions one acquisition criterion

The acquisition criterion is meaningful for the child's profile

Mentions a timeframe for the acquisition of the outcome

$\begin{array}{cc}0.3 & 0 \\ 0.6 & 5.6 \\ 0.6 & 5 . \\ 0 & 0 \\ 0 & 0 \\ 0 & 0\end{array}$

0
5.6
5.6
0
0
0
7.8
11.1
13.1
11.1
1.3

0

TABLE 3 | Binomial logistic regression predicting high quality ratings across GFS II criteria where predictions were found to be significant.

\begin{tabular}{|c|c|c|c|c|c|c|}
\hline \multirow[b]{2}{*}{ Predictors of high quality ratings } & \multirow[b]{2}{*}{ B } & \multirow[b]{2}{*}{ SE } & \multirow[b]{2}{*}{ Wald } & \multicolumn{3}{|c|}{$95 \% \mathrm{Cl}$} \\
\hline & & & & Lower & $\operatorname{Exp}(B)$ & Upper \\
\hline \multicolumn{7}{|l|}{ FOCUSES ON PARTICIPATION IN DAILY ROUTINE } \\
\hline $\begin{array}{l}\text { Living in a bottom IDACI local authorities } \\
\text { (wealthiest) rather than in middle range and bottom } \\
\text { ranked }\end{array}$ & 3.32 & 0.77 & 18.65 & 6.14 & $27.75^{\star \star}$ & 125.34 \\
\hline Having SLC, rather than ASD and other diagnoses & 2.13 & 0.68 & 9.66 & 2.19 & $8.38^{*}$ & 32.02 \\
\hline \multicolumn{7}{|c|}{ SPECIFIES THE BEHAVIOR THE CHILD SHOULD PERFORM } \\
\hline $\begin{array}{l}\text { Living in a middle range IDACI local authorities when } \\
\text { compared to }\end{array}$ & 2.27 & 0.72 & 9.99 & 2.37 & $9.70^{\star}$ & 39.68 \\
\hline $\begin{array}{l}\text { Living in a bottom IDACI local authorities } \\
\text { (wealthiest) }\end{array}$ & 3.01 & 0.56 & 28.54 & 6.73 & $20.32^{\star \star}$ & 61.31 \\
\hline Attending special settings & 1.17 & 0.42 & 7.85 & 1.42 & $3.23^{\star}$ & 7.33 \\
\hline \multicolumn{7}{|l|}{ HIGHLIGHTS A SKILLS USEFUL FOR PARTICIPATION } \\
\hline Living in a middle range IDACI local authorities & 2.27 & 0.72 & 9.99 & 2.37 & $9.70^{*}$ & 39.68 \\
\hline Living in a bottom IDACI local authorities (wealthiest) & 3.19 & 0.56 & 33.05 & 8.22 & $24.44^{\star \star}$ & 72.65 \\
\hline Attending special settings & 1.91 & 0.39 & 23.66 & 3.13 & $6.72^{\star \star}$ & 14.61 \\
\hline \multicolumn{7}{|l|}{ MENTIONS ONE ACQUISITION CRITERION } \\
\hline Attending special settings & 1.95 & 0.50 & 15.70 & 2.62 & $6.99^{\star \star}$ & 18.68 \\
\hline Having SLC, rather than ASD and other diagnoses & 1.66 & 0.684 & 97.86 & 1.38 & $5.27^{\star}$ & 20.12 \\
\hline
\end{tabular}

${ }^{*} p<0.05,{ }^{* *} p<0.001$. 
TABLE 4 | Percentage of high quality outcome ratings per type of setting across GFS II criteria.

\begin{tabular}{|c|c|c|}
\hline & $\begin{array}{l}\text { Mainstream settings } \\
N \text { outcomes }=722\end{array}$ & $\begin{array}{c}\text { Special settings } \\
N \text { outcomes }=156\end{array}$ \\
\hline Focuses on participation in daily routine & 1.4 & 2.6 \\
\hline Specifies the behavior the child should perform & 2.1 & 6.4 \\
\hline Highlights a skills useful for participation & 1.7 & 10.3 \\
\hline Mentions one acquisition criterion & 1 & 6.4 \\
\hline The acquisition criterion is meaningful for the child's profile & 0 & 1.3 \\
\hline Mentions a timeframe for the acquisition of the outcome & 0 & 0 \\
\hline
\end{tabular}

TABLE 5 | Percentage of high quality outcome ratings per type of need across GFS II criteria.

\begin{tabular}{|c|c|c|c|}
\hline & $\begin{array}{c}\text { ASD } \\
N \text { outcomes }=433\end{array}$ & $\begin{array}{c}\text { OTHER } \\
N \text { outcomes }=376\end{array}$ & $\begin{array}{c}\text { SLC } \\
N \text { outcomes }=69\end{array}$ \\
\hline Focuses on participation in daily routine & 0.9 & 1.3 & 7.2 \\
\hline Specifies the behavior the child should perform & 3 & 1.9 & 7.2 \\
\hline Highlights a skills useful for participation & 3.7 & 2.1 & 5.8 \\
\hline Mentions one acquisition criterion & 1.2 & 2.1 & 5.8 \\
\hline The acquisition criterion is meaningful for the child's profile & 0.2 & 0.3 & 0 \\
\hline Mentions a timeframe for the acquisition of the outcome & 0 & 0 & 0 \\
\hline
\end{tabular}

series of binomial logistics regressions conducted, looking at the likelihood of having high quality outcomes depending on local authority, type of school, and type of need.

Because the assumption of proportional odds required to perform ordinal logistic regression was not met, the outcome variables (quality criteria) were converted into dichotomous variables where low quality includes not at all and somewhat and high quality includes much and very much ratings, and binomial logistics regressions conducted. For the analyses, high quality ratings were defined as the indicator. Results show that the wealthiest (bottom IDACI group) local authorities are more likely to have high quality outcomes in terms of focusing on participation in daily routines $(\mathrm{OR}=27.75, p<0.001)$, specifying the behavior that the child should perform $(\mathrm{OR}=20.32$, $p<0.001$ ) and highlighting a skill that is useful for the child's participation (OR $=24.44, p<0.001)$. Top IDACI local authorities (most deprived) were defined in the analyses as the first to be compared to the intercept, followed by the middle ranking IDACI local authorities, followed by the bottom IDACI local authorities.

Similarly, Table 4 shows the distribution of ratings per type of settings. Special schools are more likely to specify the behavior the child is supposed to perform ( $\mathrm{OR}=3.23, p=0.005)$, to highlight a skill that is useful for participation (OR $=6.72, p<0.001)$ and to mention one acquisition criterion ( $\mathrm{OR}=6.99, p<0.001$ ), when compared to mainstream EHC plans (see Table 3).

Table 5 illustrates the distribution of high quality ratings per type of need. As shown in Table 3, children with SLC are significantly more likely to have higher quality outcomes in their EHC plans, in particular concerning the focus on participation in daily routines (OR-8.38, $p=0.002$ ) and concerning the mention of one acquisition criterion ( $\mathrm{OR}=5.27, p=0.015)$, when compared to children in the two other diagnostic groups.
In sum, a child living in a more affluent area and attending a special setting, is more likely to have higher quality outcomes designed for her in her EHC plans when compared to a child living in a more deprived area and attending a mainstream setting, despite the overall poor quality across contexts.

\section{Relationships Between the Profile of Needs Observed and the Quality of the Outcomes}

Results show that the higher the number of reported needs related to mental functions, the higher the quality of the outcomes written for those children, specifically in relation to how much they focus on participation in a daily routine $(r=0.33, p=0.005)$, the extent to which they specify the details of what the child should be doing ( $r=0.39, p=0.001)$, the extent to which they specify skills that are useful for participation $(r=0.39, p=0.001)$ and the extent to which they include an acquisition criterion ( $r=0.27$, $p=0.020$ ). Additionally, children with a higher number of selfcare needs had more outcomes in their EHC plans specifying a timeframe for the outcomes to be achieved $(r=0.36, p=0.002)$.

\section{DISCUSSION}

The purpose of this study was to examine inequalities in the current EHC planning process for children with SEND in the wealthiest and the most deprived areas of England (in Greater London). Specifically, we examined the patterns of need of young children with SEND aged 4-8 as reported in their EHC plans, the quality of the outcomes written for them, and the relationship between needs and outcomes. Overall, our results show a pattern of needs that is similar amongst children indiscriminate of their diagnoses, with an emphasis on learning needs, self-care, mental health and communication. Additionally, we found that the 
overall quality of the outcomes designed for these children is low. We have also found inequalities in terms of quality of needs descriptions and outcomes: children living in a more affluent area and attending a special setting, are more likely to have higher quality outcomes and needs descriptions in her EHC plans when compared to children living in more deprived areas and attending mainstream settings, despite the overall poor quality of the plans across contexts. Lastly, our results show that some needs are associated with higher quality outcomes.

The study is the first to provide an in-depth analysis of the content of the needs' section in the EHC plans of children with SEND. The use of the ICF-CY in this process enabled the identification of more specific categories of need, beyond the general diagnostic label. By examining these specific needs, it was possible to observe that the profiles of the children included in our sample were very similar, despite the existence of different diagnostic categories. This is not entirely surprising given the fact that the majority of children in this sample have either ASD or SLC, who often present a profile of needs in similar domains (Charman et al., 2015). On the other hand, this finding is in line with previous international research showing that young children with different diagnosis may have similar functioning profiles (Castro and Pinto, 2015) and that their learning and participation patterns are independent of their diagnostic category (Pinto et al., 2018). It is striking, however, to observe that all of the analyzed EHC plans still mentions the actual diagnostic label as a main need, within the health needs section of the EHC plans, when this was perhaps unnecessary, as it is not providing specific individual information on needs that can be used for intervention purposes (Lollar and Simeonsson, 2005); the term "need" often seems to be applied as synonym of diagnosis within the plans. This use of terminology by some professionals who wrote the EHC plans illustrates the previously highlighted claim that there is a gap between the ideology of the current SEND policy, focusing on holistic provision, and the way that it has been put into practice (Castro and Palikara, 2016): although the policy is clear that specific and individualized needs of the children should be reported in relation to the education, health and social care domains, in practice some of the professionals who wrote the EHC plans seem to still use the term "need" from a medical model approach. In fact, it was not a primary aim of this study to identify the diagnostic categories of the children whose plans were analyzed, as there is not a requirement of the new SEND policy to do so. However, most EHC plans included this information within the health needs section. Regarding the outcomes, children with SLC seem to have higher quality ratings in two of the criteria for assessing outcomes; this might related to the fact that these children often have specialized support staff working specifically with their language and communication difficulties alongside the school, thus providing very specific info to be included in the plans. Such specialized support is often not present when children have other diagnostic labels.

One important result of this study is that the EHC plans are not holistic and provision not integrated: the education section is still privileged as the section where to include most of the information, while the sections on health and social care are either empty or they include information of diagnostic nature.
We argue that the fragmented structure of the EHC plan, which separates the three domains, contributes to this presentation; it is impossible in real life to separate education, health and social care domains, as they are constantly interacting to define the individual's functioning (World Health Organization, 2001; Rakap, 2015). Over the last 20 years, the WHO has endorsed a definition of "health status" that moves beyond the mere existence of medical issues, to include a "State of complete physical, mental, and social well-being, and not merely the absence of disease or infirmity" (...) "health-related state is the level of functioning within a health-related domain (...). Health related domains are those areas of functioning that, while they have a strong relationship to a health condition, are not likely to be the primary responsibility of the health system, but rather of other systems contributing to wellbeing' (World Health Organization, 2001, p. 228). From this point of view, education needs are also health needs. Together, they are functioning needs and should not be split. This argument is the essence of the transactional approaches to development, which posit that at each moment in time the child is the result of this dynamic, unbreakable interaction; these approaches have been conceived as the core developmental framework for early childhood intervention (Sameroff, 2009), according to which all needs are health needs as long as they have implications on functioning and well-being. This new approach to health that has been widely endorsed over the last 20 years following WHO recommendations is aligned with the new SEND policy in England where participation is regarded as the ultimate outcome of provision, however, in practice, the plans still contemplate three separate sections for the different types of needs, and as illustrated in the current study, health needs are still seen from a medicalized point of view. Perhaps the EHC plans should contain one single narrative, where the whole child is described in detail, with consideration for the interaction between health, education and social care domains.

The results also show that learning and applying knowledge as well as mental health functions (especially those related to emotional regulation) seem to be a primary need in most children, across diagnostic categories, or that these seem to be described in more detail by those writing the plan. More interestingly, affluent local authorities have richer descriptions of mental health and sensory needs when compared to the more deprived ones. We foresee two possible explanations for this phenomenon: one is that the most affluent local authorities have availability of funds to employ specialized staff to write these plans, leading to a more systematic level of detail; the other possible explanation is that most affluent parents/carers will be more in possession of the cultural capital required to support the teams in writing the most appropriate plan for their children, when compared to parents/carers from the most deprived areas. Given the fact that deprived boroughs are allocated additional education funds by the central government, it is likely that the latter provides a better explanation, which is also aligned with previous research findings: different rates of parental participation and satisfaction in relation to the development of statutory documents for children have been observed, which depend on the family's level of income, and 
racial/ethnic background (Jung, 2011; Blackwell and Rossetti, 2014). However, future research should look into this matter in more detail, adding evidence to the currently available body of research in this field, by gathering the local authority point of view.

Similarly, special education settings provide significantly more detail about certain types of need that mainstream settings, either because the needs of the children attending this type of setting are in higher number and more apparent, or because special settings employ more specialist staff. Looking into differences in professional practice between specialist and mainstream settings should certainly be the subject of future research too; 40 years from Warnock we seem to be far from reaching the all-inclusive holistic provision that had been highly-regarded then. One could argue that the concerns raised by Warnock in 2005 regarding the need for special schools as an alternative (and segregated) form of provision could be the solution to the problem of low quality service provision in mainstream settings; however, this does not help to overcome the visible social inequalities by which more affluent local authorities seem to have higher quality plans. Our results highlight the clear inequality-based status quo of the current SEND provision, which is likely to be more dependent on the parents/carers own cultural capital than on the qualifications of the SEND staff or on the practices adopted within the SEND system.

The low quality outcomes included in EHC plans has been highlighted recently in the literature as one of the main issues with the current SEND policy (Castro et al., 2019) and is examined further in the current study, which shows that richer areas and special setting have higher quality outcomes than the more deprived and mainstream ones. Therefore, we seem to be moving further away from the inclusion and diversity agenda in at least two domains: social class and educational placement. If a child attends a special setting in an affluent local authority, it is likely he or she will have a higher quality EHC plan than another child attending a mainstream educational setting in a deprived local authority.

We argue that a new model for training staff on developing the different sections of the plan, including outcomes, should be adopted as a standardized and intrinsic component of SEND training qualifications, integrated in the Code of Practice. Such training should be research informed and based on frameworks that have been proven successful in improving the quality of the written material; the ICF, for example, has been successfully adopted in training sessions aimed at improving the quality of outcomes in EHC plans (Castro et al., 2018), but also in the development of other statutory documents (Maia et al., 2012) and general goal setting for children with disabilities (McLeod and Bleile, 2004); coaching models of professional development have also proved successful in training professionals for effective, holistic and multi-disciplinary early childhood intervention (Snyder et al., 2015). Despite this, our results also show that the ability to write good quality outcomes may be above and beyond the training of staff: looking at the relationship between the patterns of needs observed and the outcomes developed for these children, we can see that the higher the frequency of mental functions regarded as main need, the higher the quality of the outcomes written in than plan. One possible explanation for this, in line with previous research, is that it might be easier to write outcomes for children with more severe needs, whose accomplishments might be more specific and definable, than for those with higher functioning profiles; because children with more severe disabilities might make progress in smaller steps than higher functioning children, outcomes design might be more straight forward with the former (Boavida et al., 2010). Similarly, it has been found that the presumption of higher competence in students with developmental disabilities resulted in goals and objectives that are focused on learning the general curriculum, increased overall time in the mainstream classrooms, and more special education related services delivered in mainstream settings (Blackwell and Rossetti, 2014).

The evidence resulting from this research suggests that good quality provision requires a more standardized system in place, contemplating specific training on frameworks that can help the production of higher quality documents across contexts, but also contemplating a system where multi-disciplinary teams have the working conditions to know the child and the family to a level where they can be specific about their needs regardless of the severity of the functioning profile.

\section{LIMITATIONS}

Although highly trustworthy and well-aligned with the literature in the field, the results from this study should be interpreted with caution, especially as the main sample of EHC plans was gathered in Greater London. Although the study presents sufficiently strong evidence to enable generalization, a nation-wide study would be helpful to be able to claim that the issues observed here are similar to those faced by families, professionals and local authorities in other particular areas of the country, with similar deprivation issues as the ones included in this study. Similarly, the number of children and respective EHC plans coming from the wealthiest local authorities was relatively small, and although the assumptions for conducting statistical analyses were carefully examined, it would have been relevant to look at other affluent regions in the country. However, we consider the findings of the study provide a reliable indication of the inequalities currently observed in SEND provision, which should be the focus of deeper and more extensive exploration in future research.

\section{CONCLUSION}

The current study is the first to provide an in-depth analysis of the needs patterns of young children in receipt of EHC plans, of the outcomes written for these children, and of the relationship between needs and outcomes, as included in their plans. In response to the first research question, results show a pattern of needs that is similar amongst children indiscriminate of their diagnoses, a significantly higher number of sensory and mental functions' needs being reported in wealthier areas, and a significantly more detail regarding some types of needs in specialist settings. In response to the second research question, outcomes are of poor quality across EHC plans, but marked 
differences were observed between the most affluent and the most deprived local authorities (in favor of the most affluent ones) and between types of educational setting. In response to the third research question, results show a relationship between children's needs and outcomes, where the higher the frequency of needs related to mental functions (of emotional nature), the higher the quality of outcomes.

The main insight resulting from this study is that current status quo of the SEND policy and service provision in England is still very much marked by social inequality, in parallel with standards of professional development that need urgent intervention. Forty years on from Warnock, there is no standard model of provision aiming to unite professionals in teams focused on holistic provision. The result of this, is a cohort of children who might not be receiving effective support, in particular those from deprived backgrounds. Forty years on from Warnock we still need a new, evidence-based model for SEND training and provision to tackle inequalities and implement effective early childhood intervention.

\section{ETHICS STATEMENT}

This study was carried out in accordance with the recommendations of name of guidelines, name of committee

\section{REFERENCES}

Barton, L. (2005). Special Educational Needs: An Alternative Look. (A Response to Warnock M. 2005: Special Educational Needs-A New Look). Disability Archive UK.

Blackwell, W. H., and Rossetti, Z. S. (2014). The development of individualized education programs: where have we been and where should we go now? Sage Open 4:2158244014530411. doi: 10.1177/2158244014530411

Boavida, T., Aguiar, C., McWilliam, R. A., and Pimentel, J. S. (2010). Quality of individualized education program goals of preschoolers with disabilities. Infants Young Children 23, 233-243. doi: 10.1097/IYC.0b013e3181e45925

Boesley, L., and Crane, L. (2018). 'Forget the health and care and just call them education plans': SENCO s' perspectives on Education, Health and Care plans. J Res Special Educ Needs 18, 36-47. doi: 10.1111/1471-3802.12416

Bruder, M. B. (2000). Family-centered early intervention. Topics Early Childhood Spec. Educ. 20, 105-115. doi: 10.1177/027112140002000206

Caldwell, B. M. (1970). The rationale for early intervention. Exceptional Children 36, 717-726. doi: 10.1177/001440297003601002

Caldwell, B. M. (1974). A decade of early intervention programs: what we have learned. Am. J. Orthopsychiatry 44, 491-496. doi: 10.1111/j.1939-0025.1974.tb00902.x

Cameron, A. C., and Trivedi, P. K. (1990). Regressionbased tests for overdispersion in the Poisson model. J. Econometrics 46, 437-464. doi: 10.1016/0304-4076(90)90014-K

Carpenter, B., and Campbell, L. (2008). The changing landscape of early childhood intervention in the United Kingdom. Infants Young Children 21, 142-148. doi: 10.1097/01.IYC.0000314485.54582.ac

Carpenter, B., Schloesser, J., and Egerton, J. (2009). European Developments in Early Childhood Intervention. Available online at: http://www.eurlyaid.net/ (retrieved January 15, 2019)

Castro, S., Ferreira, T., Dababnah, S., and Pinto, A. I. (2013). Linking autism measures with the ICF-CY: Functionality beyond the borders of diagnosis and interrater agreement issues. Devel. Neurorehabilitation 16, 321-331. doi: $10.3109 / 17518423.2012 .733438$

Castro, S., Grande, C., and Palikara, O. (2019). Evaluating the quality of outcomes defined for children with Education Health and Care plans in England: with written informed consent from all subjects. All subjects gave written informed consent in accordance with the Declaration of Helsinki. The protocol was approved by the University of Roehampton Ethics Committee.

\section{AUTHOR CONTRIBUTIONS}

SC-K conceived the study, managed data collection, conducted data analysis, and reported the study in the current format. OP supported the conception of the study, data collection management, and reporting of the study in its current format. CG supported data analysis and reporting on the study in its current format.

\section{FUNDING}

This research study was funded by The Froebel Trust (RCH-17-2016) and by the British Academy/Leverhulme Trust (SG142214).

\section{ACKNOWLEDGMENTS}

The authors are grateful to the families and children who released their EHC plans for research. a local picture with global implications. Res. Dev. Disabilities 86, 41-52. doi: 10.1016/j.ridd.2019.01.003

Castro, S., and Palikara, O. (2016). Mind the gap: the new special educational needs and disability legislation in england. Front. Educ. 1:4. doi: $10.3389 /$ feduc.2016.00004

Castro, S., Palikara, O., Gaona, C., and Eirinaki, V. (2018). "No policy is an island": how the ICF international classification system may support local education planning in England. Disabil. Rehabili. doi: 10.1080/09638288.2018.1529828. [Epub ahead of print].

Castro, S., and Pinto, A. (2015). Matrix for assessment of activities and participation: Measuring functioning beyond diagnosis in young children with disabilities. Devel. Neurorehabilitation 18, 177-189. doi: $10.3109 / 17518423.2013 .806963$

Castro, S., Pinto, A., and Simeonsson, R. J. (2014). Content analysis of Portuguese individualized education programmes for young children with autism using the ICF-CY framework. Eur. Early Childhood Educ. Res. J. 22, 91-104. doi: 10.1080/1350293X.2012.704303

Cave, C., and Maddison, P. (1980). A survey of recent research in special education. Int. J. Rehabil. Res. 3:305. doi: 10.1097/00004356-198006000-00038

Charman, T., Ricketts, J., Dockrell, J. E., Lindsay, G., and Palikara, O. (2015). Emotional and behavioural problems in children with language impairments and children with autism spectrum disorders. Int. J. Lang. Commun. Disorders 50, 84-93. doi: 10.1111/1460-6984. 12116

Department for Education and Department of Health (2015). SEND Code of Practice 0-25 Years. Statutory Guidance for Organisations Which Work with 1245 and Support Children and Young People with Special Educational Needs and Disabilities. London: UK Government.

Department of Education and Science (1978). Warnock Committee Report. London: HMSO.

Dunst, C. J. (2000). Revisiting "rethinking early intervention." Topics Early Childhood Special Educ. 20, 95-104. doi: 10.1177/0271121400020 00205

Dunst, C. J., Bruder, M. B., and Espe-Sherwindt, M. (2014). Family capacitybuilding in early childhood intervention: do context and setting matter? School Community J. 24, 37-48. 
Dunst, C. J., and Trivette, C. M. (2009). Using research evidence to inform and evaluate early childhood intervention practices. Topics Early Childhood Spec. Educ. 29, 40-52. doi: 10.1177/0271121408329227

Faulkner, D., and Coates, E. A. (2013). Early childhood policy and practice in England: twenty years of change. Int. J. Early Years Educ. 21, 244-263. doi: 10.1080/09669760.2013.832945

Green, W. H. (2003). Econometric Analysis. Upper Saddle River, NJ: Prentice Hall.

Halpern, R. (2000). Early childhood intervention for low-income children and families. Handbook Early Childhood Intervention 2, 361-386. doi: 10.1017/CBO9780511529320.019

Jung, A. W. (2011). Individualized Education Programs (IEPs) and Barriers for Parents from Culturally and Linguistically Diverse Backgrounds. Multicultural Educ. 19, 21-25.

King, G., Strachan, D., Tucker, M., Duwyn, B., Desserud, S., and Shillington, M. (2009). The application of a transdisciplinary model for early intervention services. Infants Young Children 22, 211-223. doi: 10.1097/IYC.0b013e3181abe1c3

Legislation.gov.uk (2014). Children and Families Act 2014. Available online at: http://www.legislation.gov.uk/ukpga/2014/6/contents/enacted (accessed January 11, 2015).

Lollar, D. J., and Simeonsson, R. J. (2005). Diagnosis to function: classification for children and youths. J. Devel. Behav. Pediatrics 26, 323-330. doi: 10.1097/00004703-200508000-00012

Maia, M. S., Santos, P., Ferreira, M. S., Tavares, A., Alves, S., and Pinheiro, S. (2012). The use of the International Classification of Functioning, Disability and Health (ICF) framework on educational planning: Promoting an environmental approach. Int. J. Cross Discipl. Subjects Educ. 2, 970-977. doi: 10.20533/ijcdse.2042.6364.2012.0138

McLeod, S., and Bleile, K. (2004). The ICF: a framework for setting goals for children with speech impairment. Child Lang. Teach. Therapy 20, 199-219. doi: 10.1191/0265659004ct272oa

McWilliam, R. A. (2005). Goal Functionality Scale. Nashville, TN: Vanderbilt University Medical Center.

National Children's Bureau (2017). Off the Radar: Shining a Light on Children Whose Rights and Welfare are at Risk. London: National Children's Bureau.

Norwich, B. (2014). Changing policy and legislation and its effects on inclusive and special education: a perspective from England. Br. J. Special Educ. 41, 403-425. doi: 10.1111/1467-8578.12079

Palikara, O., Castro, S., Gaona, C., and Eirinaki, V. (2018a). Capturing the voices of children in the education health and care plans: are we there yet? Front. Educ. 3:24. doi: 10.3389/feduc.2018.00024

Palikara, O., Castro, S., Gaona, C., and Eirinaki, V. (2018b). Professionals' views on the new policy for special educational needs in England: ideology versus implementation. Eur. J. Spec. Needs Educ. 6257, 1-15. doi: 10.1080/08856257.2018.1451310

Parton, N. (2006). 'Every Child Matters': The shift to prevention whilst strengthening protection in children's services in England. Children Youth Services Rev. 28, 976-992. doi: 10.1016/j.childyouth.2005. 10.002
Pinto, A. I., Grande, C., Coelho, V., Castro, S., Granlund, M., and Björck-Åkesson, E. (2018). Beyond diagnosis: the relevance of social interactions 1313 for participation in inclusive preschool settings. Dev. Neuorrehabil. 22, 390-399. doi: 10.1080/17518423.2018.1526225

Rakap, S. (2015). Quality of individualised education programme goals and objectives for preschool children with disabilities. Eur. J. Spec. Needs Educ. 30, 173-186. doi: 10.1080/08856257.2014.986909

Sameroff, A. J. (ed.). (2009). The Transactional Model of Development: How Children and Contexts Shape Each Other. Washington, DC: American Psychological Association. doi: 10.1037/11877-000

Shonkoff, J. P., Phillips, D. A., and National Research Council (2000). "Rethinking nature and nurture," in From Neurons to Neighborhoods: The Science of Early 1321 Childhood Development (Washington, DC: National Academies Press).

Simeonsson, R. J., Bailey, D. B., Huntington, G. S., and Comfort, M. (1986). Testing the concept of goodness of fit in early intervention. Infant Mental Health J. 7, 81-94. doi: 10.1002/1097-0355(198621)7:1<81::AID-IMHJ2280070109>3.0.CO;2-3

Smith, T., Noble, M., Noble, S., Wright, G., McLennan, D., and Plunkett, E. (2015). The English Indices of Deprivation 2015. London: Department for Communities and Local Government.

Snyder, P., Hemmeter, M. L., and Fox, L. (2015). Supporting implementation of evidence-based practices through practice-based coaching. Topics Early Childhood Special Educ. 35, 133-143. doi: 10.1177/0271121415594925

UN (2006). United Nations Convention on the Rights of Persons with Disabilities. New York, NY: UN Publishing.

Unesco (1994). “The Salamanca Statement and Framework for Action on Special Needs Education," in World Conference on Special Needs Education; Access and Quality 1994.

Warnock, M. (2005). Special Educational Needs: A New Look. London. Philosophy of Education Society of Great Britain.

World Health Organization (2001). International Classification of Functioning, Disability and Health: ICF. Geneva: World Health Organization.

World Health Organization (2007). International Classification of Functioning, Disability and Health: Children and Youth Version: ICF-CY. Geneve: World 1340 Health Organization.

Conflict of Interest Statement: The authors declare that the research was conducted in the absence of any commercial or financial relationships that could be construed as a potential conflict of interest.

The handling editor declared a past co-authorship with one of the authors, OP.

Copyright (C) 2019 Castro-Kemp, Palikara and Grande. This is an open-access article distributed under the terms of the Creative Commons Attribution License (CC BY). The use, distribution or reproduction in other forums is permitted, provided the original author(s) and the copyright owner(s) are credited and that the original publication in this journal is cited, in accordance with accepted academic practice. No use, distribution or reproduction is permitted which does not comply with these terms. 